\title{
Thermomagnetic Features of Central Brazil, between regions of Trans-Brazilian Lineament (TBL) and São Francisco Craton (SFC)
}

Suze Nei Pereira Guimaraes, Fabio Pinto Vieira, Valiya M. Hamza

National Observatory - ON/MCTIC - Department of Geophysics - Geothermal Laboratory (LabGeot)

Copyright 2019, SBGf - Sociedade Brasileira de Geofísica

This paper was prepared for presentation during the $16^{\text {th }}$ International Congress of the Brazilian Geophysical Society held in Rio de Janeiro, Brazil, 19-22 August 2019.

Contents of this paper were reviewed by the Technical Committee of the $16^{\text {th }}$ International Congress of the Brazilian Geophysical Society and do not necessarily represent any position of the SBGf, its officers or members. Electronic reproduction or storage of any part of this paper for commercial purposes without the written consent of the Brazilian Geophysical Society is prohibited.

\begin{abstract}
We report in this work progress obtained in analysis of thermomagnetic features of the region in the southern parts of the Tocantins state and northern parts of Goias state, central Brazil. The approach makes use of data collected in aeromagnetic surveys. Techniques of shading applied to vertical derivative of residual magnetic field has been used in identifying the magnetic lineaments and spectral analysis in the estimative its depths. The results obtained reveal the existence of a set of near linear magnetic features in the region between $48^{\circ} \mathrm{W}$ and $51^{\circ} \mathrm{W}$ longitude and between of $12^{\circ} \mathrm{S}$ and $14^{\circ} \mathrm{S}$ latitude. This is also an area of moderate micro-seismic activity and recent studies point to anomalous geothermal conditions in the upper crust. However, direct evidences on occurrence of magmatic intrusions at shallow crustal levels are absent. In the present work, we advent the hypothesis that features identified in aeromagnetic survey data are indicative of fracture systems which allow up flow of carbonic fluids transporting geothermal heat. The presence of carbonic gas flow has observed at sites of thermal springs in the region.
\end{abstract}

\section{Introduction}

Data acquired in aeromagnetic surveys have been employed in several studies of geomagnetic field of geologic provinces in central Brazil. Focus of most of these investigations have been in mineral and hydrocarbon exploration at shallow depths in the upper crust. Very few attempts have been made in using aeromagnetic data to explore crustal structure at deepmost levels. Guimaraes et al. (2014) used techniques of spectral analysis of aeromagnetic data in understanding vertical distributions of magnetization in deep crustal layers. This line of approach was pursued in a more recent study of magnetized crustal blocks in the adjacent cratonic region by Guimaraes and Hamza (2019).

In the present work, we examine the vertical derivative of residual magnetic field making use of the geophysical techniques of shading. The depth of these magnetic sources was inferring by spectral analysis of residual magnetic field. The location of the study area covers a region between $48^{\circ} \mathrm{W}$ and $51^{\circ} \mathrm{W}$ (longitude) and between of $12^{\circ} \mathrm{S}$ and $14^{\circ} \mathrm{S}$ (latitudes).

\section{Geologic Context of the Study area}

The area of study includes the northern parts of Goias state and southern parts of Tocantins state, in central Brazil. The main rock types are Brasilia and Araguaia belts of late Proterozoic age. Tectonic features of the Trans-Brazilian Lineament are evident in the western parts (Schobbenhaus, 1975). Orthogneisses and greenstones belts of the Brasilia belt (Tocantins Structural Province) and the Bambui group (São Francisco craton) are present on the eastern side. The regional distributions of these geological units are illustrated in the simplified geologic map of Figure 1.

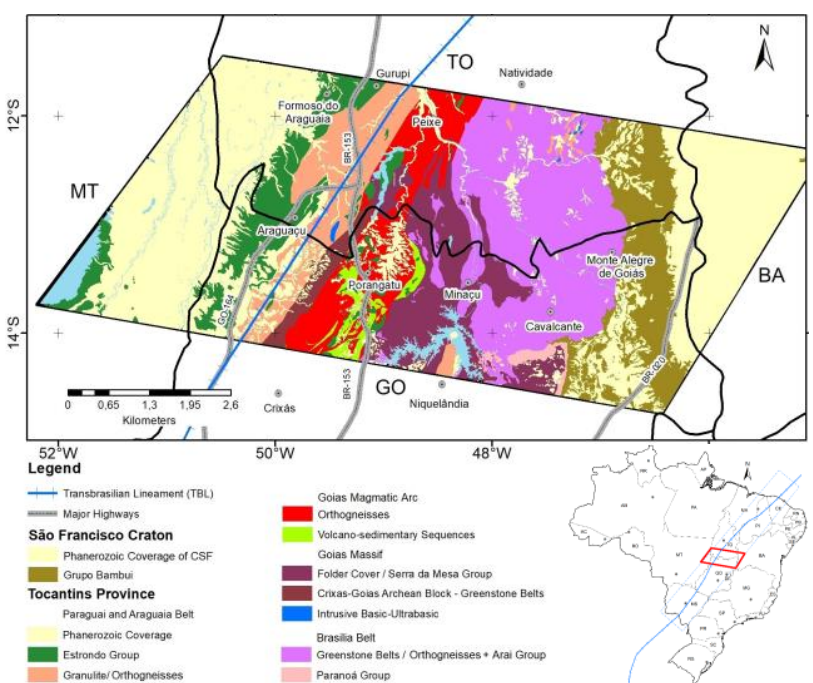

Figure (1): Simplified geologic map indicating location of the study area (modified by CPRM, 2014).

\section{Acquisition of data}

The present work is based on data sets compiled under the projects designated as Brazil-Canada Geophysical PGBC (1976 - cod. 1020), Area 2 (2004) and Area 5 (2006) of Goias, Tocantins (2006 - cod.1073), complement of Tocantins (2007 - cod. 1071) and Rio Formoso (2014 cod.1126). These are public domain data sets, made available by CPRM for academic research purposes. The earlier database (PGBC) have nominal altitude of $200 \mathrm{~m}$ and line spacing of $2 \mathrm{~km}$. The databases acquired after 2000 have similar characteristics of acquisition with the flight lines in the N-S direction, spacing of $500 \mathrm{~m}$ and nominal flight altitude of $100 \mathrm{~m}$.

Different types of processing techniques were applied for these two types of database. For PGBC data, corrections were made for levelling, micro-levelling, 
filtering. This was followed by removal of geomagnetic field components (diurnal and principal - IGRF), which allowed derivation of the residual or anomalous field. To group of data after 2000, the residual magnetic field already was acquired with all corrections and levelling applied. Following this, suture techniques were employed in generating a unified data set. The degree of coherence of this union was verified with application of directional filters. The map of residual magnetic anomaly is presented in Figure (2). Also indicated in this figure is the parallelogram of the segment selected for analysis of lineaments.

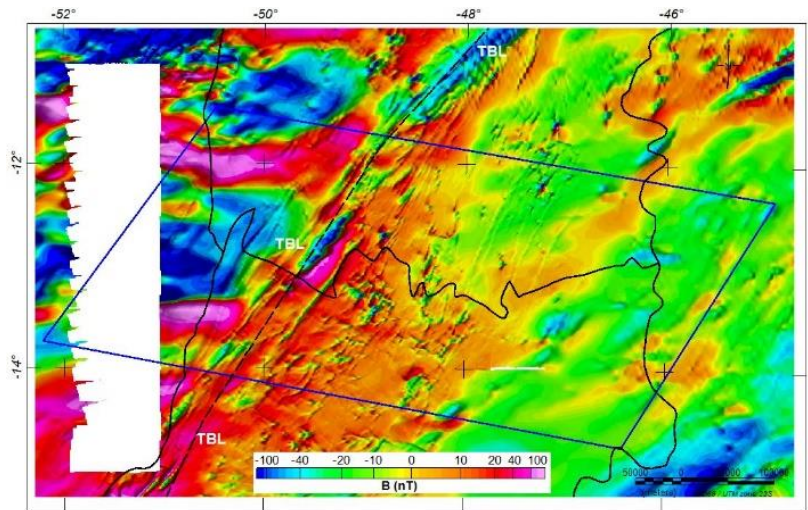

Figure (2): Map of residual magnetic anomaly in the study area. The white patch indicates area with lack of suitable data. The parallelogram indicate of the segment selected in analysis of lineaments.

The methods adopted for identifying the depths of the magnetic sources are based on the supposition that the anomalies observed in the crustal magnetic field are produced by a distributed ensemble of prismatic bodies. So, the logarithm of the mean power spectrum generated by these anomalous magnetic sources are related to the depths of the top of the ensemble.

Techniques of spectral analysis were employed for determination of depths of magnetic sources in subsurface. The spectral analysis program (in MATLAB) allowed for changes in size of search windows, allowing calculation the depth of magnetic sources in different parts of the study area. It also allowed calculation of depth to top $(T)$ and bottom (B) of magnetic sources. The results obtained are presented in Table 1.

Table (1) - Depth to top (T) and bottom (B) of magnetic sources obtained in spectral analysis by the centroid method, for data in the study area (Guimaraes et al. 2014).

\begin{tabular}{cccccc}
\hline ID & $\begin{array}{c}\text { LON } \\
\text { (W) }\end{array}$ & $\begin{array}{c}\text { LAT } \\
\text { (S) }\end{array}$ & $\begin{array}{c}\text { Shallow } \\
\text { T/ B }\end{array}$ & $\begin{array}{c}\text { Mean } \\
\text { T/ B }\end{array}$ & $\begin{array}{c}\text { Deep } \\
\text { T/ B }\end{array}$ \\
\hline M2 & 49.52 & 12.08 & 0.42 & 0.97 & 16.03 \\
(300) & & & 0.83 & 3.67 & 33.30 \\
\hline M5 & 49.98 & 12.87 & 0.43 & 1.08 & 12.63 \\
(225) & & & 0.87 & 5.77 & 28.28 \\
\hline M10 & 45.74 & 13.05 & 0.14 & 3.66 & 17.79 \\
$(150)$ & & & 1.88 & 6.76 & 32.79 \\
\hline
\end{tabular}

\section{Analysis of Vertical Derivative}

Study of magnetic expressions of tectonic lineaments require enhancement of short wavelength anomalies. This is usually achieved by examining vertical derivatives of the residual field. Thus, maps of vertical derivatives are often employed in outlining tectonic lineaments. Magnetic imprints of lineaments arise from emplacement of thin sheets of material of relatively higher magnetic susceptibility. Clearly, fracture systems triggered by the tectonic process is responsible for the formation of a system of parallel fractures.

Large-scale tectonic features of the study area in the present work are the Trans-Brazilian Lineament (TBL) on the western side and the Sao Francisco craton (SFC) on the eastern side. Pioneering studies of TBL were carried out by Schobbenhaus et al (1975) and Brito Neves \& Cordani (1991). Analysis of the vertical derivative of the residual magnetic field in the study area indicated the presence of magnetic lineaments associated with TBL. These are actually closely spaced linear magnetic features, as illustrated in the map of Figure (3). The blue colored line is the lineament identified in geologic studies. The red colored near-linear features in this figure have been considered as indicative of fracture zones in the basement rocks. There are five main fracture zones to the left the TBL. An additional set of three fracture zones can be identified to the west of TBL. The white segments in this map refer to areas that lack the needed spectral resolution.

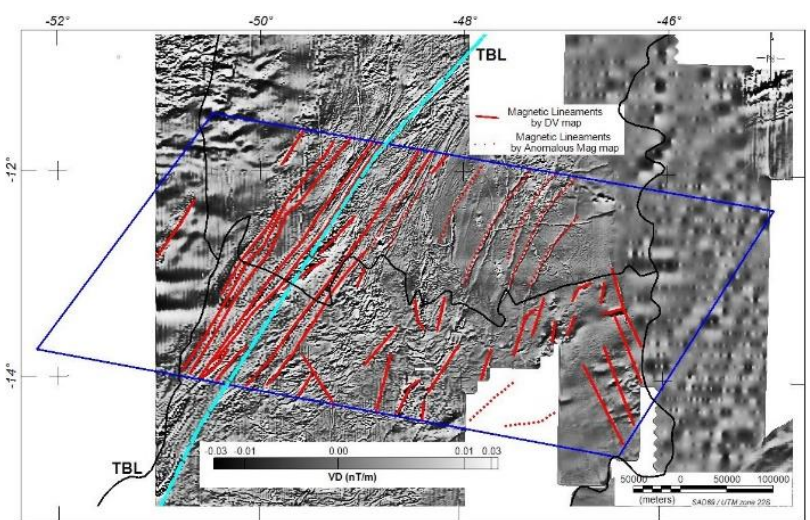

Figure (3): Distribution of vertical derivative of the residual magnetic field in the study area. Mapping done using the technique shading. The white areas in the map refer to areas which lack spectral resolution.

More than ten fracture zones with magnetic expressions can easily be identified in the map of Figure 3. These have NE-SW trending directions. Note that the lateral spacing of such features is relatively small, generally in the range of 5 to $10 \mathrm{~km}$. The presence of such closely spaced anomalies may be considered as indication that TBL in the study area is composed of a set of parallel quasi-linear fracture zones.

Fracture zones also occur in the region between TBL and SFC. However, their spacing is relatively large, of the order of several tens of kilometers. The directions of these fracture zones are also NE-SW. Following Gholipour et al. (2016) such differences in fractur spacing has been considered as indication of fundamental differences in the deep tectonic process. It is also interesting to note that fracture zones are absent in the cratonic region on the eastern side of the study area. This may be considered as indication that the cratonic area is composed of relatively 
unbroken structural elements with practically no significant contrast in their magnetic properties.

\section{Deep Crustal Structure along Profiles}

Deep crustal structure of the study area may be understood by considering vertical variations in Moho depths, Curie temperatures and heat flow along selected profiles. The locations of these profiles are indicated in Figure (4). The first profile (P1) have NE-SW direction, between $50^{\circ}$ and $48^{\circ} \mathrm{W}$ (long) and coincides with the TBL. It is situated in the western part of the study area. The second profile (P2) is a W-E profile cutting across the structural provinces of Tocantins and São Francisco. The third profile (P3) have NE-SW direction, between $47^{\circ}$ and $46^{\circ} \mathrm{W}$ (long) and is in the SFC.

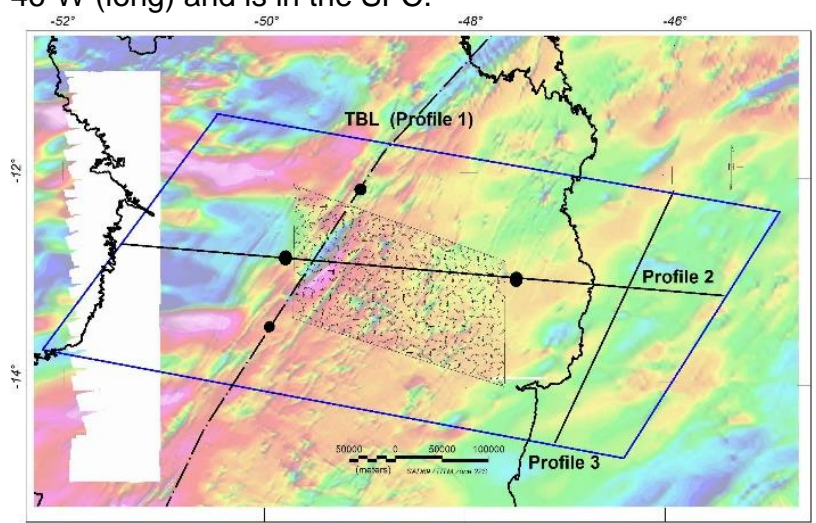

Figure (4): Locations of profiles selected in the present work. The highlighted area is indicative of geothermal anomaly.

Values of Moho depths along the profiles are based on results reported in seismic studies of the region (Assumpcao et al, 2013). Similarly, results of spectral analysis of aeromagnetic data reported by Guimarães et al (2004) was employed in setting the thickness of magnetized crustal layer. Heat flow values were derived using the procedure reported by Guimaraes and Hamza (2019). Variations of Moho depth and curie temperatures along the middle profile (Profile 2) is illustrated in Figure (5).
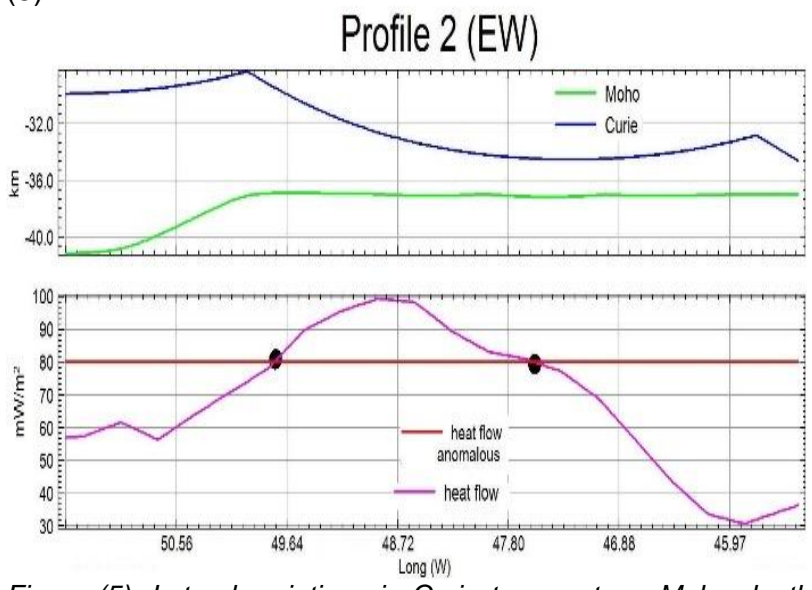

Figure (5): Lateral variations in Curie temperature, Moho depth and heat flow along the central region (Profile 2) in the study area.

In this Figure (5), the top panel indicates variations in Moho depth and Curie temperatures, while the bottom panel illustrates heat flow variations. It is evident that there is a prominent heat flow anomaly in the region between TBL and SFC.

Variations of Moho depth and curie temperatures along top and bottom profiles are illustrated in Figure (6). In this case, the variations in Moho depth and Curie temperatures are much subdued. Also, it is evident that heat flow variations are much less subdued along the northern (Profile 1) and southern (Profile 3) parts of the study area.
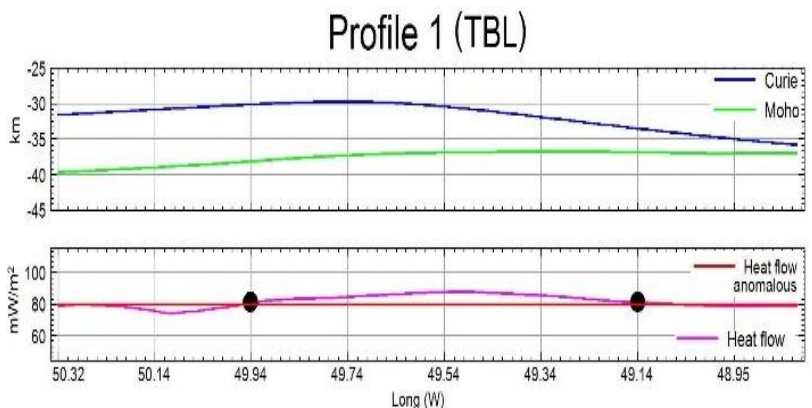

Profile 3 CSF
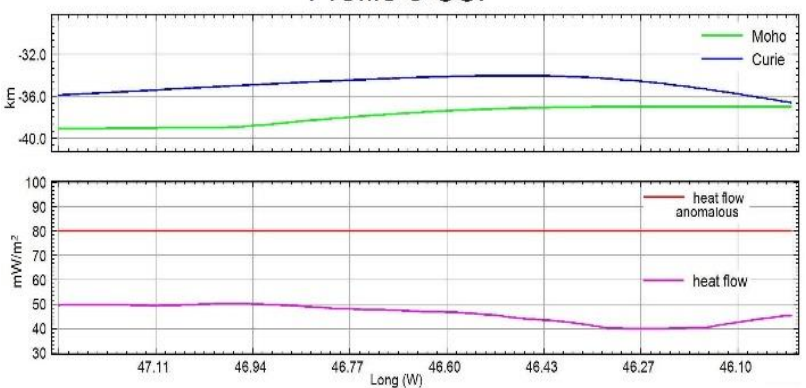

Figure (6): Lateral variations in Curie temperature, Moho depth and heat flow along profiles in the western (Profile 1) and eastern (Profile 3) parts of the study area.

\section{Spacing between elements of the Lineament}

Geologic lineaments are usually defined in literature as interpreted lines that has visible relations with geometrical features of terrain forms, such as valleys and slopes. A notable feature of the lineaments in Figure 3 is the high degree of parallelism between the fracture zones. This is often interpreted as consequence of thermo-mechanical nature of the rupture process in geological materials (see for example: Schultz and Fossen, 2008).

The spacing between fracture zones can be measured in terms of the average distance between features in the lineament. According to Ladeira and Price (1981) the average spacing between elements rapidly approach asymptotic limits, as illustrated in the top panel of Figure 7. The spacing is achieved on small time scales (bottom panel of Figure 7). However, there are indications that spacing is weakly related to the layer thickness. Gholipour et al. (2016) argue that the lineaments that exhibit parallel trends over long distances has similarities with those observed in segmentation processes occurring geothermal activities.

According to Lamour (2018) and Lamour et al (2017) changes in fracture spacing is induced by upflow of hot material. In the case of rapid up flow of high temperature molten magmatic material, the failure of confining rock strata take place on relatively short time scales. The 
resulting fracture zone is an elongated feature with parallel side walls. Thus, pulses of magma eruptions lead to sets of closely spaced fracture zones. On the other hand, in the case of weaker effusive eruptions internal pressure buildup takes place on relatively longer time scales, allowing for opening of fractures with larger spacing. In other words, fracture spacing may be considered as indication of the type of fluid flows during occurrence of lineaments. However, effusive eruptions imply transport of geothermal heat by upwelling flow of fluids rich in water or carbon dioxide. Hence areas with wider fracture spacings are likely to be associated with localized heat flow anomalies.
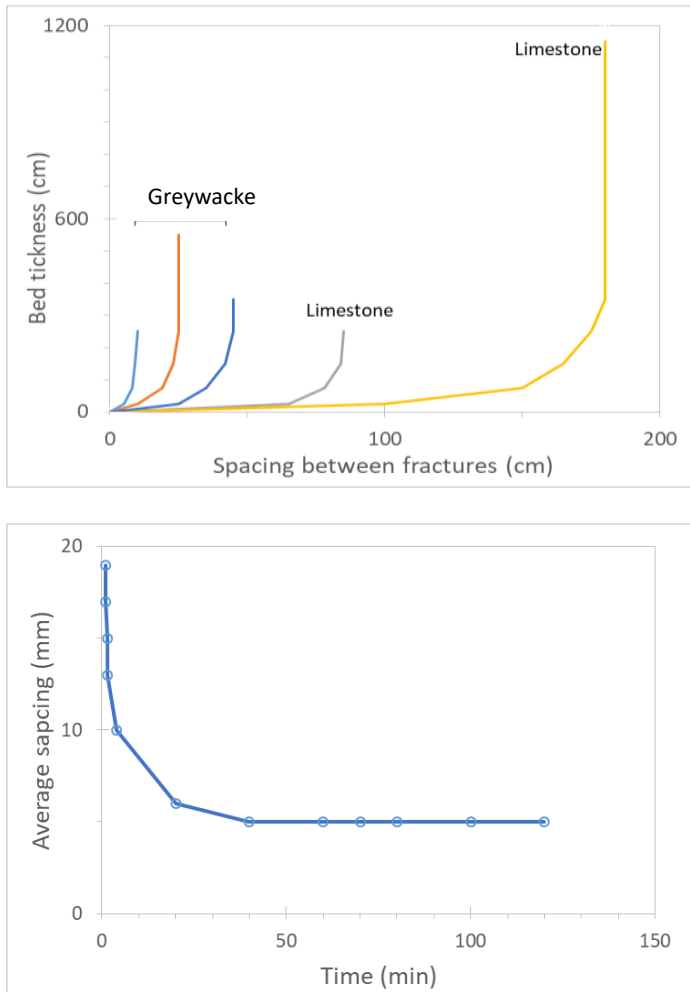

Figure (7): The top panel illustrate the relation between fracture spacing and bed thickness. The bottom panel illustrate time scale involved in laboratory simulations of fracture spacing (Modified after Ladeira and Price, 1981).

In the region of TBL the spacing of fracture zones is less than $10 \mathrm{~km}$, while the lengths are greater than several hundreds of kilometers. These have NE-SW trending directions. On the other hand, in the region between TBL and SFC the lateral spacing of fractures is relatively larger, generally in the range of 10 to $50 \mathrm{~km}$.

\section{Geothermal Field of the region between TBL and SFC}

A recent geothermal study by Descovi and Vieira (2019) have identified an anomalous geothermal field in the region between TBL and SFC. In this area, geothermal gradients vary from 15 to $55^{\circ} \mathrm{C} / \mathrm{km}$ while thermal conductivity values are in the range of 2.2 to $3.2 \mathrm{~W} / \mathrm{m} . \mathrm{K}$. Consequently, heat flow values are in the range 40 to 160 $\mathrm{mW} / \mathrm{m}^{2}$. The heat flow map derived from the results obtained in the present work are illustrated in Figure (8). Note that heat flow in the region between TBL and SFC reach values in excess of $80 \mathrm{~mW} / \mathrm{m}^{2}$. The SFC have the lowest values heat flow, generally less than $50 \mathrm{~mW} / \mathrm{m}^{2}$.

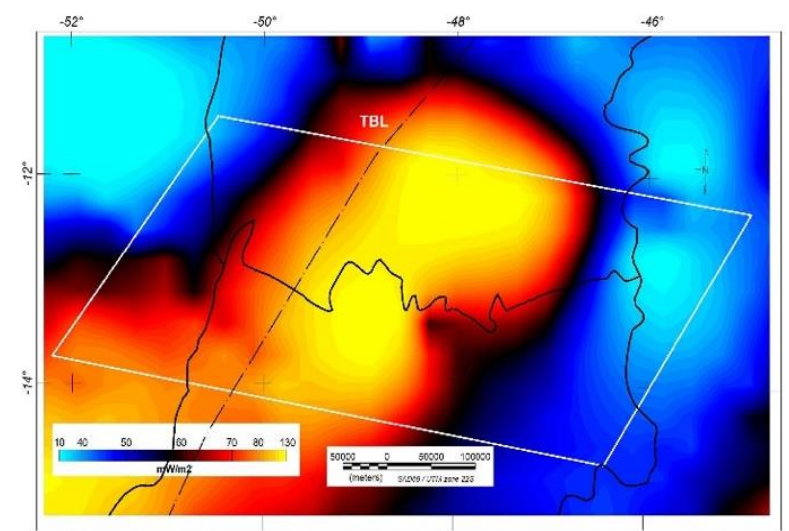

Figure (8): Heat flow map of northern Goias and Southern Tocantins, the region between TBL and SFC.

It is clear that the region between anomalous geothermal conditions prevail in the region between TBL and SFC in the northern parts of the state of Goias and southern parts of the State of Tocantins. However, direct evidences on occurrence of magmatic intrusions at shallow crustal levels are absent. Descovi and Vieira (2019) suggested the possibility that anomalous geothermal conditions arise from supplementary heat transport by up flow of carbonic fluids. Hence, we advent the hypothesis that features identified in aeromagnetic survey data are indicative of fracture systems which allow transport of geothermal heat. The presence of carbonic gas flow has observed at sites of almost all thermal springs in this region.

\section{Conclusions}

Techniques of shading applied to vertical derivative and spectral analysis of residual magnetic field has been used in identifying and characterization magnetic lineaments. The results obtained reveal the existence of a set of near linear magnetic features in the region between $48^{\circ} \mathrm{W}$ and $51^{\circ} \mathrm{W}$ longitude and between of $12^{\circ} \mathrm{S}$ and $14^{\circ} \mathrm{S}$ latitude. Along the western side of the study area, the spacing of magnetic lineaments is in the range of 5 to 10 $\mathrm{km}$. On the other hand, the spacing of fracture zones is in the range of 10 to $50 \mathrm{~km}$ along the eastern segment of the study area. This difference in the spacing of fracture zones have been considered as indicative of changes in the nature of deep-seated tectonic processes.

The magnetic sources depth in the region inferred by the spectral analysis technique have the range of 35 to $50 \mathrm{~km}$, be that in big part of the TBL region the thickness between the Curie and Moho surfaces presents a difference of $10 \mathrm{~km}$. In the CSF region, this difference becomes almost null $(2 \mathrm{~km})$, showing that almost all the crust is magnetized.

The region between TBL and SFC has moderate microseismic activity and recent studies point to anomalous geothermal conditions in the upper crust. However, direct evidences on occurrence of magmatic intrusions at shallow crustal levels are absent. In the present work, we advent the hypothesis that features identified in aeromagnetic 
survey data are indicative of fracture systems which allow up flow of carbonic fluids transporting geothermal heat. The presence of carbonic gas flow has observed at sites of thermal springs in the region.

\section{Acknowledgments}

This study is part of the research project of the first author, recipient of a post-doctoral scholarship by PNPD/CAPES, at the Department of geophysics of the National Observatory - ON/MCTIC. The third author is recipient of a scholarship granted by Brazilian National Research Council - CNPq (Process No. 306755/2017-3).

\section{References}

Assumpção, M., Bianchi, M., Julià, J., Dias, F.L., França, G.S., Nascimento, R., Drouet, S., Pavão, C.G., Albuquerque, D.F., Lopes, A.E., 2013. Crustal thickness map of Brazil: data compilation and main features. J. S. Am. Earth Sci. 43, 74-85.

Brito Neves, B.B. and Cordani U.G., 1991. Tectonic evolution of South America during the Late Proterozoic, Precambrian Res., vol.53, p.23-40.

CPRM, Serviço Geológico do Brasil. 2014. Data base online. Programa Geologia do Brasil. Rio de Janeiro.

Descovi and Vieira, 2019. Regions of anomalous geothermal fields in the State of Tocantins, Central Brazil. International Journal of Terrestrial Heat Flow and Applied Geothermics. Vol.2, n.1, p.30-37.

Gholipour1, A.H., Cosgrove, J.W. and Ala, M., 2016. New theoretical model for predicting and modelling fractures in folded fractured reservoirs. Petroleum Geoscience, Vol. 22, pp. 257-280.

Guimaraes, S.N.P., Ravat, D. and Hamza, V.M., 2014. Combined use of Centroid and Matched Filtering Methods in determining thermomagnetic characteristics of the crust in the structural provinces of Central Brazil. Tectonophysics 624-625 (2014) pp. 87-99.

Guimaraes, S.N.P. and Hamza, V.M., 2019. Thermomagnetic features of Pirapora area, central Brazil. International Journal of Terrestrial Heat Flow and Applied Geothermics. Vol.2, n.1, p.9-16.

Lamur, A., 2018, Development, impact and longevity of fractures in magmatic, volcanic and geothermal systems. Ph.D. Thesis, University of Liverpool, UK.

Lamur, A., Kendrick, J., Eggertsson, G., Wall, R., Ashworth, J. and Lavallée, Y., 2017. The permeability of fractured rocks in pressurised volcanic and geothermal systems: Scientific Reports, v. 7.

Ladeira, F.L. and Price, N.J. 1981. Relationship between fracture spacing and be thickness. Journal of Structural Geology, 3, 179-183.

Schobbenhaus, C. 1975. Carta Geológica do Brasil ao Milionesimo. DNPM, Brasília 114p.

Schobbenhaus, C.C.L. Ribeiro, L.A. Oliva, J.T. Takanohashi, A.G. Lindenmayer, J.C. Vasconcelos and V.
Orlandi, 1975. Folha Goiás SD.22, with explanatory text. In: Carta Geológica do Brasil Milionésimo, edited by $\mathrm{C}$. Schobbenhaus, DNPM, Brasília, DF, Brazil.

Schulz R.A.S. and Fossen, H., 2008. Terminology for structural discontinuities. AAPG Bulletin, v. 92, no. 7, pp. 853-867. 